\title{
Clients Input Improves Satisfaction on HIV and AIDS Program
}

Lawrence Chidzambwa ( $\square$ chidzaml@yahoo.com)

IrsiCaixa Institut de Recerca de la Sida https://orcid.org/0000-0002-1450-2277

IIm Kassam

AIDS Support Organisation

\section{Research article}

Keywords: Client participation, HIV and AIDS, Appreciative Inquiry, Social Constructivism, Program improvement

Posted Date: March 3rd, 2020

DOI: https://doi.org/10.21203/rs.3.rs-15685/v1

License: (c) (i) This work is licensed under a Creative Commons Attribution 4.0 International License. Read Full License 


\section{Abstract}

Background: AIDS Vancouver is a donor funded non-profit organization that supports people living with HIV and AIDS (PLWHA). Like many health providers there is need to look for effective less costly methods of not only delivering services but improve the quality and coverage as well. Literature indicates that the participation of clients is an effective low-cost method of improving service. PLWHA are reluctant to participate in client input initiatives because of negative reactions in society to their condition. Innovative methods to engage clients need to be utilized.

Methods: An initial survey was conducted to determine the base satisfaction level. The survey also indicated areas for improvement. Consultation sessions were conducted with clients, volunteers and staff on which issues to tackle and how. This process has been repeated for three consecutive years. Appreciative Inquiry (Al)and Social Constructivism (SC) theories were selected as guidelines on client engagement. Al was selected to encourage participants to use the strengths and resources around them to improve the program. Social Constructivism was selected for its ability to combine individual perspectives in constructing meaning that is acceptable to all participants.

Results: Annual surveys have become a useful tool to determine the client satisfaction level on the program. They have also highlighted the dynamic issues related to supporting our clients. The follow-up consultation sessions have generated 41 proposals of which 26 have been implemented successfully. Client satisfaction is up, client participation in running the program continues to grow. The cost implications are minimal, yet the benefits are significant. Client participation raised program satisfaction level by 16 percentage points after one year and has maintained the satisfaction level high in two consecutive years.

Conclusions: Client participation was essential in improving the satisfaction level of the program. It was important to create the space for clients to participate and also build trust with clients. Clients have a lot of knowledge about their conditions and provide valuable input. Their contribution is mainly on social aspects rather than technical aspects. These social aspects are essential in improving the client experience and need to be included in improvement initiatives.

\section{Background}

Health providers are shifting their focus from being reactive to being pro-active (Ontario Framework, Ministry of Health and Long Term Care, 2018). This helps to reduce the escalating costs in healthcare and enable higher returns on invested funds. Their focus is shifting to preventive and personal care management particularly in long-term care (MaRS, 2019). The new approach requires higher client input in decision making. Whether the cooperation is called patient and family as partners, patient and public involvement, patient-centred care, shared decision making, patient experiences, co-design, user involvement and many such terms that are used inter-changeably, the objectives are very similar if not the same. At the core of these approaches is the increased empowering of the patient. The new methods advocate for user or client participation in their care. It has been pointed out that the word "patient" as used in health care suggests a passive receiver of services (Ferrer, 2015) (thebmj, 2018). In this article client or user are used to avoid the negative connotation attached to "patient" (Shevel I, 2009). The clients referred in the article are people who have been diagnosed with HIV and are registered beneficiaries to a Supplementary Grocery Program (SGP).

The aim of the project was to promote the participation of clients in improving a program in which they are beneficiaries. This article discusses how client participation has successfully transformed a program that supports people diagnosed with HIV. AIDS Service Organisations are aware of the reluctance of $\mathrm{HIV}+$ people to participate in programs and selected methods that we thought would provide the best results.

\section{Organizational context}

AIDS Vancouver was formed in 1983 by a group of gay men in response to the AIDS crisis that was threatening to wipe out the community in the city. The group of gay men got together to compile information and distribute it in Vancouver as was being done in other major cities in USA especially in New York and San Francisco. This led to the creation of the organization which now provides services like Community Case Management, Health Promotion, HIV Helpline as well as the Supplementary Grocery Program. The Supplementary Grocery Program was started as a means of providing grocery items to those who were not able or were finding it difficult to support themselves. Currently the Supplementary Grocery Program distributes selected nutritionally valuable grocery items to people living with HIV and AIDS (PLWHA) in the Lower Mainland of British Columbia, Canada. The program distributes an average of 450 grocery bags every distribution week. The regular food items include fresh fruits and vegetables, dairy items, eggs, protein rich items like fish and peanut butter and canned meat, grain items and some hygienic items. Having an adequate supply of food helps in adherence to medication (Young, Wheeler, McCoy, \& Weiser, 2014). Having adequate food also helps to maintain a healthy level of CD4 count as living with HIV and AIDS has a complex dependent interaction with nutrition (Sztam, Fawzi, \& Duggan, 2010). Research shows that some of the nutritional effects of HIV infection are decrease in dietary intake, malabsorption of nutrients especially with gastrointestinal infections, increase in resting energy expenditure linked to opportunistic infections (Sztam, Fawzi, \& Duggan, 2010). People living with HIV require $20 \%$ to $30 \%$ more nutrients than an average person (WHO, 2003). This becomes a challenge with deteriorating health condition. The program is an essential contributor to the health of PLWHA. It was felt that for satisfaction level to improve, it was essential for clients to participate in the program.

AIDS Vancouver is a non-profit organisation which relies on donor funding for the continued operation of its programmes. Volunteers play in crucial role in ensuring that the programs remain operational. Volunteers average between 4 to 6 months active engagement period as some find work, return to school, etc. Therefore, the knowledge base about the program is concentrated among the clients. A number of these clients have been diagnosed with HIV for more than ten years. There is considerable knowledge within the community on how to sustain the life of a person living with HIV or AIDS from a nutritional point of view. With access to limited funding AIDS Vancouver needs an efficient low-cost method to improve the quality of service to its clients hence the need for client participation. 
Before the project, clients were encouraged and are still participating as volunteers in the grocery distribution activity as a visual encouragement to other clients to use the service. PLWHA have challenges accessing services because the environment is not inclusive enough (Cain, et al., 2014). In addition, within this community are distinct groups who would like their specific circumstances considered. Some of the groups are LGBT, indigenous people, visible minorities, immigrants, single parents and the elderly. With such a variety of members it is natural to have different perceptions and expectations about the services the agency provides. Steps have been taken to provide a low barrier and inclusive service for grocery supplement access. For example, a women-only time slot has been set for every grocery week to accommodate women who, for historical reasons, find it difficult to mix with men. The organization has a set of values that have been established over its course of existence. Client participation and empowering PLWHA to participate in decision making on factors that impact them are included as core values. However, it was observed that client participation in decision making needed to improve, hence initiating the project.

\section{Background to health client participation}

Improving the quality, efficiency and safety of health service delivery as well as improving the client experience is a challenge faced by many health providers around the world (Baker, Judd, Fancott, \& C, 2016). Besides improving the quality of service, providers are looking at different methods to contain the spiraling cost of healthcare (Fudge, Wolfe, \& McKevitt, 2008). One of the strategies showing promising results in dealing with these challenges is the engagement of the clients in finding ways to improve. The involvement of clients in quality improvement in the health sector has been advocated for some years now. Publicly funded programs and research projects have been implemented to develop, encourage and share ways that lead to effective client participation. In Canada the Health Council of Canada, the Canadian Health Research Foundation, universities and many other organizations have been funding initiatives to bring client involvement to reality and show the benefits (Brosseau \& Verma, 2011). The results are encouraging. However, it has also been shown that more work needs to be done to encourage service providers to incorporate client participation into the organizational culture (OntarioHealth, 2019) (Roy \& Cain,

2001) (DepartmentofHealth, 2019).

Advocating for PLWHA to participate in developing policies for their community began in the early days of the epidemic. This principle was accepted at international level leading to the endorsement of the Declaration of Commitment on HIV/AIDS by 189 United Nations member countries in 2001 (United Nations, 2001) under the name Greater Involvement of People with AIDS (GIPA). Most of the AIDS service organizations have taken this on board and many of the long-term volunteers are the beneficiaries of this approach. However, some organizations include PLWHA in menial roles (Roy \& Cain, 2001) so that they appear as meeting the criteria required by funding organizations who demand evidence of user involvement. This can be a barrier to client participation.

The International Association of Public Participation (iap2, 2015), applies a spectrum of public participation in engaging the public on issues of interest. It states that, depending on the individuals and the issue at hand, client participation moves along this spectrum back and forth. The spectrum stretches from inform, consult, involve, collaborate to empower. To get clients to be higher than involve or Figure collaborate stage of participation requires effort in creating collaborative environments and support structures. Effort is required to create an engaging environment where stakeholders have opportunities to contribute and are supported with resources to fulfill their expected responsibilities (Payne \& Briscoe, 2010). Within these structures, stakeholders need to be given authority to evaluate the implementation of the decisions they carried out. That is the empowering stage.

Insert Figure 1 here.

For health services, a model for client engagement is proposed by applying some of the guidelines offered by the iap2 Spectrum of Engagement (Carman, et al., 2013). This takes the form of a multi-dimensional model for patient and family engagement as shown in figure 1 . The notable addition to the spectrum of public participation model is the kind of engagement at each organizational level. The article states that this is significant because much emphasis has been put on the operational side of engagement without proper structures being put in place at the higher levels to ensure sustainability in engagement.

\section{Client participation challenges}

Health users on the majority are not health experts in services delivery. They do not have the clinical or health administrative knowledge or experience that the professionals have acquired. Expecting healthcare users to contribute to clinical aspects at the same level as clinicians is unrealistic. Therefore, their participation should not be evaluated on technical terms. As consumers they know what they want. They are experts in their needs. Users are much more informed about their medical condition than in the past (Vahdat, Hamzehgardeshi, Hessam, \& Hamzehgardeshi, 2014). They have specific expectations of the services they receive. It is up to the service provider to match those expectations or explain why they can not meet them. The best way users can contribute is by being able to express their expectations, doubts, trust, fears and experience as clear as they can. It is the duty of the solution designers to apply the user issues into the solutions and systems they design.

Client involvement can also be viewed as a redistribution of power (Van De Bovenkamp, Trappenburg, \& Grit, 2010) (Jackson \& Sorensesn, 2006) (MaRS, 2019). This socio-political view undermines some initiatives of change. Traditionally the clinician has held all the powers over the client and dictated what takes place. Power disparity between clinicians and clients still pose a considerable challenge and needs to be addressed.

The Canadian Foundation for Health Improvement had a client come and give their account of the experience in hospital at a CEOs forum (CFHI, 2013). The experience of the client can be summarised as follows;

- The environment was dirty

- The unit itself smelled unpleasant

- Staff loudly discussed last night's party in the hallway

- Very few people introduced themselves 
- Communication with my family was minimal

- What I longed for was someone to do something with me not for me and not to me

Most of these are not clinical issues. Clinicians do not use these as metrics to measure the quality of their work. Addressing these issues was important to the patient and when she was invited to the patient advisory council these were some of her first things to address with the council. The benefits and challenges of client involvement are shown in Figure 2. The diagram indicates that besides leadership there are cultural and organizational issues that can be barriers to effective client participation. To encourage the verbalization and application of social aspects in improvement solutions, Social Constructivism and Appreciative Inquiry theories have been applied in this project.

Insert Figure 2 here.

In engaging clients, it is important to note that clients do not use the same parameters as clinicians to evaluate service. They use social aspects which include expectations and fears in addition to the clinical expectations they have.

\section{Method}

The project was set up to improve the participation of clients in the Supplementary Grocery Program (SGP). This comes from the core belief in the organization that individuals need to be empowered in order for them to determine the direction of their lives.

\subsection{Project Outline}

As a starting point the agency conducted a client survey to determine satisfaction level on the SGP in January 2017. This client survey determined that satisfaction level was at $76 \%$. Areas needing improvement like variety of products, quality of fresh produce and quality of service were pointed out in the responses. The responses also indicated that clients expected the agency to address these issues. Clients did not consider themselves as a resource. New methods of approach were therefore required not only to encourage clients to participate in improving the service but the whole organization. This led to the selection of Appreciative Inquiry as an approach that would galvanise the recognition of the resources surrounding the program that have a potential to raise the satisfaction level.

Every January since 2017 we hold a client survey to determine the client satisfaction level about the program. During the survey week co-op students from local colleges and universities who are not regularly connected with the program are requested to conduct the surveys. Notices about the forthcoming survey are distributed a month before. As clients come in to collect groceries clients are asked if they want to participate in the survey and those who agree are given a tablet to answer survey questions and those who need assistance are given a helper. A variety of question types is used including multiple choice, multiple choice grid, checkboxes and open-ended questions which require short phrase answers. The survey forms are structured in a way to rate satisfaction on the service provided, competence of staff, the variety of products, usefulness and quality of products. Questions are modified each year to collect data on issues that need more focus. After some consultations the responses are prioritized and applied to tailor the program to cover as much of clients' expectations as possible. This is done in client consultations sessions. The consultations are carried out in the Grocery Improvement Forum.

As a follow-up to the first survey we put together a group comprising of clients and staff. This is named Grocery Improvement Forum. It meets once a month to discuss how to implement the improvement ideas from clients and staff. We used a two thronged approach which on one hand encouraged the forum to recognize that there are resources around us that can be applied to improve the program. On the other hand, we used a method that encouraged bringing together and understanding ideas as participants see them and combine them to form improvement plans. These two approaches are guided by the Appreciative Inquiry theory and the Social Constructivism theory.

\subsection{Theoretical approach to the case study}

Social Constructivism and Appreciative Inquiry theories have been applied to this project because of their compatibility in elevating user aspects (McNamee, 2014). Theories enable us to compile reproducible explanation and models to support the applications. Both theories are selected on their ability to show in detail the way meaning is constructed and applied in solving problems or improving applications. The goal is to have a shared understanding or meaning based on common interest and achieved through service interactions. The interaction supports individuals to extend their understanding from the contributions made by other members of the group.

\subsubsection{Appreciative Inquiry}

Appreciative Inquiry (Al) is a theory and practice that aims to shift the perspective of organizational development by asking generative questions (Frankel \& Lenoci-Edwards, 2017). It involves appreciating the current strengths and asking questions to gain better insight into other people's needs and intentions in light of those strengths. The central message of the approach is that organizations evolve in the direction that stakeholders collectively ask questions about (Bushe G. R., 2013). The inquiry part encourages the exploration and discovery of these strengths and opportunities and being open to new possibilities. Whilst in most improvement initiatives we ask what is not working, with Al the starting point is on what is working. It is a method of generating a collective vision of a better future by first understanding the best of the past and the best of the present (Bushe G. R., 1995). This energizing starting point shows an appreciation of the positive aspects of any program and use that as a foundation. People are then encouraged to look at the future and how good it can be when the identified strengths are further utilized. This generates ideas on how the desired position can be achieved. Those ideas generated will build commitment from the participants and create a sense of ownership.

Page $4 / 11$ 
In line with Al application, the unique attributes of our program are highlighted at the start of every consultative session. For example, the fact that we provide nutritionally valuable products to the community has been applauded many times. However, because of storage challenges experienced by some clients, we offer some food items in easy to prepare format like canned beans. We noticed that canned beans were not being picked from the shelf as expected and asked during a consultation session how we can encourage clients to use beans as it is a high source of protein and fiber. It turned out that clients wanted flavored canned beans and since the time we introduced beans in different forms of sauce they have been one of the popular items. Al has assisted in moving dialogue beyond the usual rhetoric of blame, deficit, inadequacy and conflict to collaborative and identification of potential (McNamee, 2014).

\subsubsection{Social Constructivism}

Constructivism suggests that knowledge is a reality interpreted by an individual based on their perceptions and experience (Sun, Williams, \& Liu, 2005). Social constructivism assumes the relational orientation of meaning (McNamee, 2014). It states that meaning is not private but emerges from the joint activities of persons. Social constructivism is not about finding the middle ground. It is about understanding the meaning attached by other participants and verbalizing one's own. The shared understanding is then used to construct a new and shared meaning (Jackson \& Sorensesn, 2006).

In one of the follow-up sessions the meaning of quality as it relates to food items was discussed intensely. Some felt strongly about ingredients like sugar, salt and fat content. Others felt usefulness of the product in terms of being part of the main meal was quality. Still others felt it related more to fresh food items and their condition. By associating with each other people re-shaped what they associated with quality and accommodated what others attach to the word. All would appreciate the presence of alternative items that they would not normally regard as quality as they understand that others preferred those items. Social construction happens in two stages (Jackson \& Sorensesn, 2006). The first stage is interpretive understanding which is subjective as knowledge is filtered through human consciousness. Interpretive understanding assigns meaning or seeks to relate the new knowledge to that already stored in order to make sense. This supports the notion that there is no objective truth, but truth claims are relative to the interpretations obtained at the time the claims are made. For example, clients stated that there are certain foods that were claimed to be detrimental to people living with HIV in the late $80 \mathrm{~s}$ and early $90 \mathrm{~s}$. However, there has been no research to substantiate that. The second stage of social constructivism is meaning construction. Armed with the enriched understanding gained from the input of other clients, one can confirm, adjust or even reject previously subscribed meaning to the one aligned to current knowledge and understanding (Chidzambwa, 2013). The conceptual structures from individuals are the raw materials used to compile an improved service. The basis of improved service is understood by all participants.

\subsubsection{Client Consultation Sessions}

Client consultation started after results of the first survey were distributed. Copies of the results were widely distributed to staff members and clients and extra copies were made available at the notice board. One of the survey questions requested clients interested in participating in improving the program to register. These clients were then contacted for the follow-up consultation sessions. A few sessions were with individual clients and two staff members. Most sessions were with a group of clients. This was done to accommodate client preferences and availability for consultation sessions. Each session was planned for an hour with 30 minutes extension if necessary.

It was important to show that the agency is committed to open dialogue. This was done by informing the follow-up groups about the planning and decisionmaking process of the program. Each session was started by appreciating strengths of the grocery supplement program in line with the Al approach. For example, clients appreciated the distribution of organic fresh fruit and vegetables. This led to the discussion of how we ca make clients take full advantage of this. For example, recommendations on how to keep organic items fresh for longer were given and these were printed on a flyer and given to clients.

To expose clients to aspects of running the program participants were given a budget to source additional items or an item that would benefit all of the 450 people served in a week. Participants considered all factors that were relevant on top of the nutritional benefits. The taste, texture of the food item, preparation needs, storage needs, alternative to the item and general acceptability. In discussing these issues clients revealed a lot of knowledge and preferences that were not considered before. This process enriched the program. It is gratifying to see that when proposals where expressed by some clients it was mainly their colleagues who pointed out the suggestions must benefit the majority of the community and need to be sustainable.

Both clients and staff need to be prepared for their roles in client involvement (Baker, Judd, Fancott, \& C, 2016). The agency has shown a commitment to client centered service. If the participants are not adequately supported on how they can embrace these values the results may be disappointing. Leadership plays an important part in creating the space and the culture which promotes and values everyone's opinion. We created this space through the monthly client meeting. During consultations, we provided additional information on the program indicating that we trusted that they would treat this as confidential. This was reciprocated by clients by opening up on their feelings about the program instead of the usual superficial praise.

\section{Results}


Table 1

Annual Surveys Sample Questions and Responses

\begin{tabular}{|c|c|c|c|}
\hline Year & 2017 & 2018 & 2019 \\
\hline Number of responses & $N=118$ & $N=110$ & $N=152$ \\
\hline$\%$ Satisfied & 76 & 92 & 89 \\
\hline$\%$ Not Satisfied & 24 & 2 & 2.8 \\
\hline$\%$ Neutral satisfaction & & 6 & 8.2 \\
\hline Quality of products satisfaction & & $\begin{array}{l}91.8 \% \text { - Satisfied } \\
8.2 \% \text { - Unsatisfied }\end{array}$ & $\begin{array}{l}77 \% \text { Satisfactory, } \\
7 \% \text { Unsatisfactory } \\
16 \% \text { Neutral }\end{array}$ \\
\hline Frequency use of program & $\begin{array}{l}\text { All grocery days } 57 \% \\
\text { Twice monthly } 31 \%\end{array}$ & $\begin{array}{l}\text { All grocery days } 55.6 \% \\
\text { Twice monthly } 25.9 \%\end{array}$ & $\begin{array}{l}\text { All grocery days } 43.8 \% \\
\text { Twice monthly }-39.6 \%\end{array}$ \\
\hline Gender & $\begin{array}{l}79.7 \% \text { - male, } \\
17.8 \% \text { - female, } \\
2.5 \% \text { - other }\end{array}$ & $\begin{array}{l}79.4 \% \text { - male, } \\
19.6 \% \text { - female, } \\
0.9 \% \text { - other }\end{array}$ & $\begin{array}{l}77.8 \% \text { - male, } \\
16.7 \% \text { - female, } \\
5.6 \% \text { - other }\end{array}$ \\
\hline $\begin{array}{l}\text { Age range } \\
(\mathrm{M}=\text { median age })\end{array}$ & $\begin{array}{l}78.4 \%-52.5 \mathrm{M} \\
10.3 \%>65 \\
9.5 \%-30 \mathrm{M} \\
1.8 \%<20\end{array}$ & $\begin{array}{l}81.4 \%-52.5 \mathrm{M} \\
9.3 \%>65 \\
9.3 \%-30 \mathrm{M}\end{array}$ & $\begin{array}{l}74.8 \%-52.5 \mathrm{M} \\
9.1 \%>65 \\
14.7 \%-32.5 \mathrm{M} \\
1.4 \%<25\end{array}$ \\
\hline What do you think would improve the service & $\begin{array}{l}\text { OK as is }=42 \% \\
\text { More items }=33 \% \\
\text { Improve quality = } 8 \% \\
\text { Serve faster }=4 \% \\
\text { Extend serving time = } 5 \% \\
\text { Change location }=3 \% \\
\text { Serve volunteers first = 3\% } \\
\text { Other = } 2 \%\end{array}$ & & \\
\hline What would make you more satisfied with the program? & & $\begin{array}{l}\text { Nothing }=53 \% \\
\text { More items }=25 \% \\
\text { Better quality }=4 \% \\
\text { Fresh foods }=2 \% \\
\text { Better combinations = } 2 \% \\
\text { More protein }=2 \% \\
\text { Other }(<2 \% \text { each })=10 \%\end{array}$ & \\
\hline How can the grocery program be improved & & & $\begin{array}{l}\text { Nothing }=57 \% \\
\text { More items }=24 \% \\
\text { More variety }=7 \% \\
\text { More meat }=5 \% \\
\text { Change schedule = } 4 \% \\
\text { Deliver food }=3 \%\end{array}$ \\
\hline
\end{tabular}

Table 1 shows some of the questions and responses that were obtained from annual surveys. The level of satisfaction has risen. They survey results also show an increase of people who say they have nothing to suggest on improvement. One can also observe that some of the implemented suggestions have had an impact. For example, the number of people who do not take the program as a primary source of food has increased as a result of informing people about other food sources.

Table 2

Supplementary Grocery Improvement Forum Meetings

\begin{tabular}{|llll|}
\hline & $\mathbf{2 0 1 7}$ & $\mathbf{2 0 1 8}$ & $\mathbf{2 0 1 9}$ \\
\hline Number of meetings & 6 & 9 & 7 \\
\hline Number of proposals & 14 & 15 & 12 \\
\hline Proposals implemented & 10 & 8 & 8 \\
\hline Proposal category & $\begin{array}{l}\text { Product related }=12 \\
\text { Service related }=2\end{array}$ & $\begin{array}{l}\text { Product related }=8 \\
\text { Service related }=7\end{array}$ & $\begin{array}{l}\text { Product related }=6 \\
\text { Service related }=6\end{array}$ \\
\hline Cost implications & $\begin{array}{l}\text { Add cost }=7 \\
\text { Reduce cost }=1 \\
\text { No cost }=6\end{array}$ & $\begin{array}{l}\text { Add cost }=6 \\
\text { No cost }=9\end{array}$ & $\begin{array}{l}\text { Add cost }=4 \\
\text { No cost }=8\end{array}$ \\
\hline
\end{tabular}

The annual survey gives us a broader sense of the satisfaction level of clients. The consultation sessions drill down on these results to identify specific issues that are raised and then go further to recommend corrective action. A summary of the consultation or improvement forum meetings and issues discussed are shown in Table 2. The product related proposals have decreased as the service-related improvement proposals have increased. This has a direct effect on cost as most product related proposals raise the cost of the program. This indicates that improvement does not always mean adding cost. There are significant improvements that can be done which do not add any cost. The best source of the improvement suggestions is from the clients themselves. Another thing to 
note is that the suggestions keep coming. In the seven months of 2019 there have been almost as many suggestions as the whole of 2018 and already suggestions implemented are equal to those implemented in 2018. Having regular meetings with clients has helped to keep the motivation high. In the history of the program there has never been this level of client participation in decision making, implementation of improvement proposals and evaluation of the results.

The quality of the service has gone up, satisfaction level has gone up and interest in sharing ideas by all stakeholders continues to grow. This is besides the fact that there are enormous challenges faced by people living with HIV and AIDS (PLWHA) and the stigma attached to the disease which makes it difficult for the clients to freely express themselves or limits the number of people prepared to work with the community (Cain, et al., 2014). The results show that client input is an important contributing factor to the success of health programs.

\section{Discussion}

On areas that were pointed out to improve further analysis was done to determine if further information can be obtained. For example, in the 2019 Client Survey there was a question "How can the grocery program be improved?" $24 \%$ of responses indicated more which was further analyzed to determine the specifics of "more". This indicated information as shown on Fig. 3. The further analysis provided actionable information. The Supplement Grocery Improvement Forum then designed solutions to these issues highlighted.

Insert Figure 3 here.

The results from the 2018 and 2019 annual survey indicate that the participation of clients in program improvement initiative has had a big influence in raising the satisfaction level. Clients were not only consulted on what to improve but also on how to improve. Clients are also involved in evaluating the success of the implemented proposals. The clients who attend the improvement forum get involved in the implementation of the proposals. This involvement creates a sense of ownership and increases commitment.

Clients feel that socially constructing a solution to a challenge is a satisfying exercise. We have moved from suggesting solutions to issues raised to a situation where clients come up with solutions and volunteer to lead the implementation of these ideas that are adopted. The following are some of the observations.

Being open to suggestions and improving those ideas with the clients helped to show that we do not regard staff as the only authority on improvement. Clients need to be provided with feedback on the ideas that they have presented. This includes reasons why certain recommendations have been or have not been adopted. In the project we evaluated the success of the recommendations implemented in the improvement forum and at times adjusted approach to achieve expected results.

Social constructivism advocates the verbalisation of the internal dialogue. By discussing the different perspectives, the clients will be testing their ideas against the ideas of other participants. Information from different sources may change the reference criteria of individuals as stronger basis emerges from the discussions. It is therefore important that group discussions be held and as many as possible of the group members verbalise their thoughts. Words construct and generate new ideas.

To maintain momentum, the positive aspects of the program need to be highlighted and their value shared among the stakeholders. The strengths of the program need to be understood so that those aspects that are appealing can be strengthened. The negative comments need to be considered as well. For example in pursuing the answer from the survey that mentioned staff as being very helpful, we asked how can we this improve program satisfaction higher and a few suggestions were made with one stating that more respect need to shown to all clients and stop using words like "junkies" but instead talk about "substance addiction" even if the clients are not there. As a result, "Client Respect" is one of our slogans now.

Evaluation on the program performance is in an agreed format which includes client aspects. The agency applies two methods. To check the pulse on the community we use the survey. To find out more about personal choices we use the follow-up consultation sessions. It is not a straight-forward application of what we get from individuals. The personal information is considered together with the community results to determine the best way the community can benefit from the idea. Clients use social aspects to determine satisfaction about the program. Whilst the previous evaluations looked at the financials and distribution figures, social aspects as verbalized by the clients are now playing an important role in determining program success. As clients get more understanding of the regulatory and financial constraints, we see more proposals which do not add costs to the program being given. Clients have become an important resource in the improvement initiative.

\section{Conclusions}

Clients input has contributed to improving the Supplementary Grocery Program in the way that the clients appreciate. Methods of incorporating client input in implementing health programs are situational. In this project tailoring Appreciative Inquiry and Social Constructivism to encourage energized participation of clients in raising the level of service satisfaction has yielded expected results. We worked with clients to convert the unstructured recommendations into implementable ideas. The program created the space and environment in which clients feel their contributions are valued. Clients participate and at times lead the implementation of improvement initiatives. Through the Supplementary Grocery Improvement Forum monthly meetings, clients participate in the evaluation of implementation results. An increased number of clients are volunteering in the program. As a result of increased understanding of the program as well as seeing their ideas implemented and making a difference, we have seen the program satisfaction level being maintained at a high level. This has given us the motivation to continue with the consultation sessions. Enabling the exchange of ideas in a trusting space has produced positive change. We accept that social aspects are very dynamic in nature. However, they do not have to be structured to be included in solution design. They are difficult to

Page $7 / 11$ 
measure pose a challenge to include in system design. More research is required on this aspect. Also, what would be more helpful would be to understand the values that drive those preferences as values change less frequently than preferences.

\section{Abbreviations}

PLWHA

People living with HIV and AIDS

HIV

Human Immunodeficiency Virus

AIDS

Acquired immune deficiency syndrome

Al

Appreciative Inquiry

$\mathrm{SC}$

Social Constructivism

SGP

Supplementary Grocery Programme

\section{Declarations}

\section{Ethics approval and consent to participate}

1. Quality improvement and assurance studies are exempt from Research Ethics Board Review as stated by the Canadian Tri-Council Policy Statement: Ethical Conduct for Research Involving Humans (TCPS 2) 2018 as shown on the following link

Panel on Research Ethics

TCPS 2 (2018) - Chapter 2: Scope and Approach

Research Exempt from Research Ethics Board Review

Article 2.5

http://www.pre.ethics.gc.ca/eng/tcps2-eptc2_2018_chapter2-chapitre2.html

2. No consent was required because where no personal information is collected, consent is not required as stated by Canadian TCPS 2 on the link below. TCPS 2 (2018) - Chapter 10: Qualitative Research

Article 10.3

http://pre.ethics.gc.ca/eng/tcps2-eptc2_2018_chapter10-chapitre10.html

\section{Consent for publication}

Not applicable

\section{Availability of data and material}

The datasets used and/or analysed during the current study are available from the corresponding author on reasonable request.

\section{Competing interests}

The authors declare that they have no competing interests

\section{Funding}

Not applicable

\section{Authors' contributions}

Lawrence Chidzambwa designed the study and led the study. He also analyzed the data and wrote sections of the article IIm Kassam designed the study and approved the reports generated from the study. He wrote sections of this article. 
Work colleagues assisted with proof-reading the article.

\section{References}

1. Abras, c., Maloney-Krichmar, D., \& Preece, J. (2004). User-Centered Design. In Encyclopedia of Human Computer Interaction. Tousand Oaks: Sage Publications.

2. Baker, G. R., Judd, M., Fancott, C., \& C, M. (2016). Creating Engagement Capable Environments in Healthcare. Longwoods.com.

3. BCGovernment. (2017, July). Patients as Partners. Retrieved from Government of BC: http://www2.gov.bc.ca/gov/conteny/health/about-bc-s-health-caresystem/partners/patients

4. Brosseau, M., \& Verma, J. (2011). Engaging Patients to Improve Healthcare Quality. Health Quarterly Vol 14.

5. Bushe, G. R. (1995). Advances in Appreciative Inquiry an an Organization Development Intervention. Organizan Development Journal, $14-22$.

6. Bushe, G. R. (2013). The Appreciative Inquiry Model. In E. H. Kessler, Encyclopedia of Management Theory (pp. 41 - 44). Sage Publications.

7. Cain, R., Collins, E., Bereket, T., George, C. J., Prentice, T., \& Travers, R. (2014). Challenges to the involvement of people living with HIV in community-based HIV/AIDS organizations in Ontario, Canada. AIDS CARE.

8. Carman, K. L., Dardes, P., Maurer, M., Sofaer, S., Adams, K., Bechtel, C., \& Sweeney, J. (2013). Patient and Family Engagement: A framework for Understanding The Elements And Developing Interventions and Policies. Health Affairs, 223-231.

9. CFHI. (2013, ). Moving Forward with Patients and Family as Partners. Retrieved from Canadian Foundation for Health Improvement CEO Forum 2013: http://www.cfhi-fcass.ca/NewsandEvents/Events/CEOForum/ceo-forum-2013

10. Chidzambwa, L. (2013). The Social Considerations for Moving Halth Services into the Home; A Telecare Perspective. Health Policy and Technology, $10-25$.

11. Cooperrinder, D. L., Barrett, F., \& Srivastva, S. (1995). Social Construction and Appreciative Inquiry: A Journey in Organizational Theory. In D. Hosking, P. H. Dachler, \& K. Gregen, Management and Organization: Relational Alternatives to Individualism. Ashgate Publishing.

12. DepartmentofHealth. (2019, APril). Shifting the balance of power: The next steps. Retrieved from Department of Health: https://webarchive.nationalarchives.gov.uk/20100717103823/http://www.dh.gov.uk/prod_consum_dh/groups/dh_digitalassets/@dh/@en/documents/di

13. Elwyn, G. (2007). Respecting the subjective: quality measurement from the patient's perspective. British Medical Journal.

14. Ferrer, L. (2015). Engaging patients, carers and communities for the provision of coordinated/intergrated health services. Copenhagen: WHO.

15. Frankel, A. H., \& Lenoci-Edwards, J. (2017). Framework for Safe, Reliable, and Effective Care. White Paper. Institute for Healthcare Improvement and Safe \& Reliable Healthcare

16. Fudge, N., Wolfe, C. D., \& McKevitt, C. (2008). Assessing the promise of user involvement in health service development: ethnographic study. BMJ, 336.313.

17. iap2. (2015). iap2 Core Values Awards Showcase 2015. Retrieved from International Association for Public Participation: www.iap2.org

18. Jackson, R., \& Sorensesn, G. (2006). Social Constructivism. In R. Jackson, \& G. Sorensesn, Introduction to International relations Theories and Approaches 3rd edition (pp. 162-177). Oxford University Press.

19. MaRS. (2019, Jan). Retrieved from Transforming Health Market Insights Series: https://learn.marsdd.com/mars-library/transforming-health/

20. McNamee, S. (2014). Appreciative Inquiry Social Constructivism in Practice. In c. Dalsgaard, T. Meisner, \& K. Voetmann, A symphony of appreciation: Development and renewal in organisations through working with appreciative inquiry (pp. 110-139). Copenhagen: Danish Psychology Press.

21. Ontario Framework, Ministry of Health and Long Term Care. (2018, November). Preventing and Managing Chronic Diseases. Retrieved from http://www.health.gov.on.ca/en/pro/programs/cdpm/pdf/framework_full.pdf

22. OntarioHealth. (2019, April). Engaging with Patients: Stories and Success. Retrieved from Insights into Quality Improvement: http://www.hqontario.ca/Portals/0/documents/qi/qip/engaging-with-patients-en.pdf

23. Payne, D., \& Briscoe, D. (2010). Engage Others. In LEADS in a Caring Environment. Ottawa: Canadian College of Health Leadership.

24. Pickard, A., \& Dixon, P. (2004). The applicability of Constructivist user studies_how can constructivist inquiry inform service provideers and system designers. Information Research, 9(3).

25. Roy, C. M., \& Cain, R. (2001). The involvement of people living with HIV/AIDS in community based organizations: Contributions and restraints. AIDS CARE. 26. Shevel I, M. (2009). What do we call 'them'?: the 'patient' versus 'client' dichotomy. Wiley Online Library.

27. Sun, L., Williams, s., \& Liu, K. (2005). Knowledge construction in E-Learning; Designing an E-Learning Environment. Interprise Information Systems V. Netherlands: Kluver Academic Publisher.

28. Sztam, K. A., Fawzi, W. W., \& Duggan, C. (2010). Macronutrient Supplementation and Food Prices in HIV Treatment. The Journal of Nutrition, 213 - 223.

29. thebmj. (2018, November). NCBI. Retrieved from NCBI Resorces: https://www.ncbi.nlm.nih.gov/pmc/articles/PMC1116090/

30. Uden, L., \& Liu, K. (2001). Linking radical constructivism and semiotics to design a constructivist learning environment. Journal of Computing in Higher education, 34-51.

31. United Nations. (2001). Declaration of Commitment on HIV/AIDS. UNAIDS.

32. Vahdat, S., Hamzehgardeshi, L., Hessam, S., \& Hamzehgardeshi, Z. (2014). Patient Involvement In Health Care Decision Making: A review. Iranian Red Crescent Medical Journal.

33. Van De Bovenkamp, H. M., Trappenburg, M. J., \& Grit, K. J. (2010). Patient participation in collective healthcare decision making: the Dutch model. Health Expect, 73-85.

Page 9/11 
34. von Niman, B., Rodriguez-Ascaso, A., Sund, T., \& Brown, S. J. (2006). User experience design guidelines for telecare services. 8th Conference on Humancomputer interaction with mobile devuces and services. Helsinki.

35. WHO. (2003). Nutrient Requirementsfor people living with HIV/AIDS. Geneva: World Health Organisation.

36. Wiig, S., Storm, M., Aase, K., Gjestsen, M. T., Solheim, M., Harthug, S., . . Fulop, N. (2013). Investigating the use of patient involvement and patient experience in quality improvement in Norway: rhetorc or reality? BMC Health Services Research.

37. Young, S., Wheeler, A., McCoy, S., \& Weiser, S. D. (2014). A review of the role of food insecurity in adherence to care and treatment among adult and padiatric populations living with HIV and AIDS. AIDS Behav.

38. Zhu, C. (2018, May 26th). Community Engagement: A summary of theoretical concepts. Retrieved from Alberta Health Services: https://www.albertahealthservices.ca/poph/hi-poph-surv-comm-phids-engage-concepts.pdf

\section{Figures}

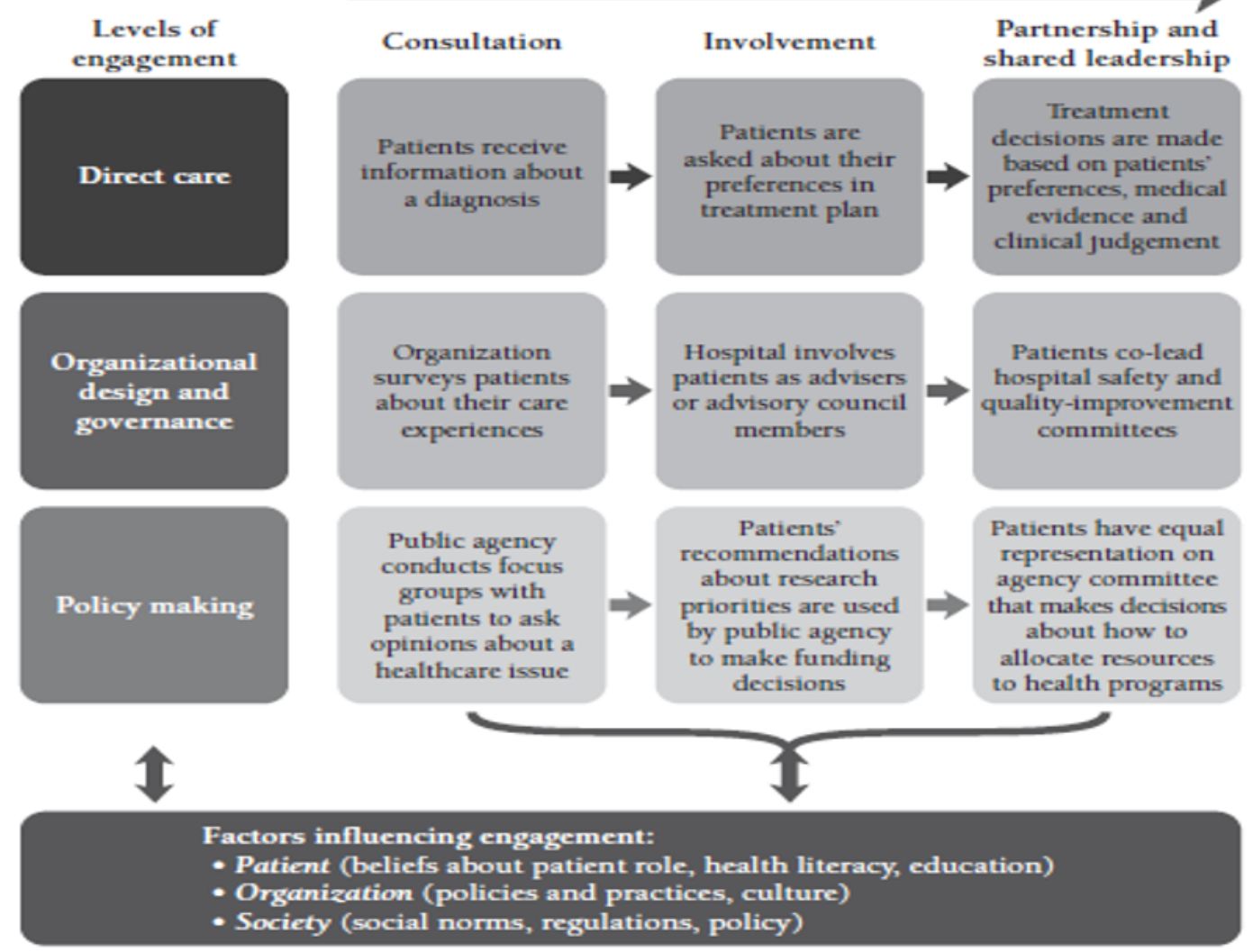

Figure 1

Multi-dimensional model for patient healthcare by iap2 (Carman, et al., 2013) 


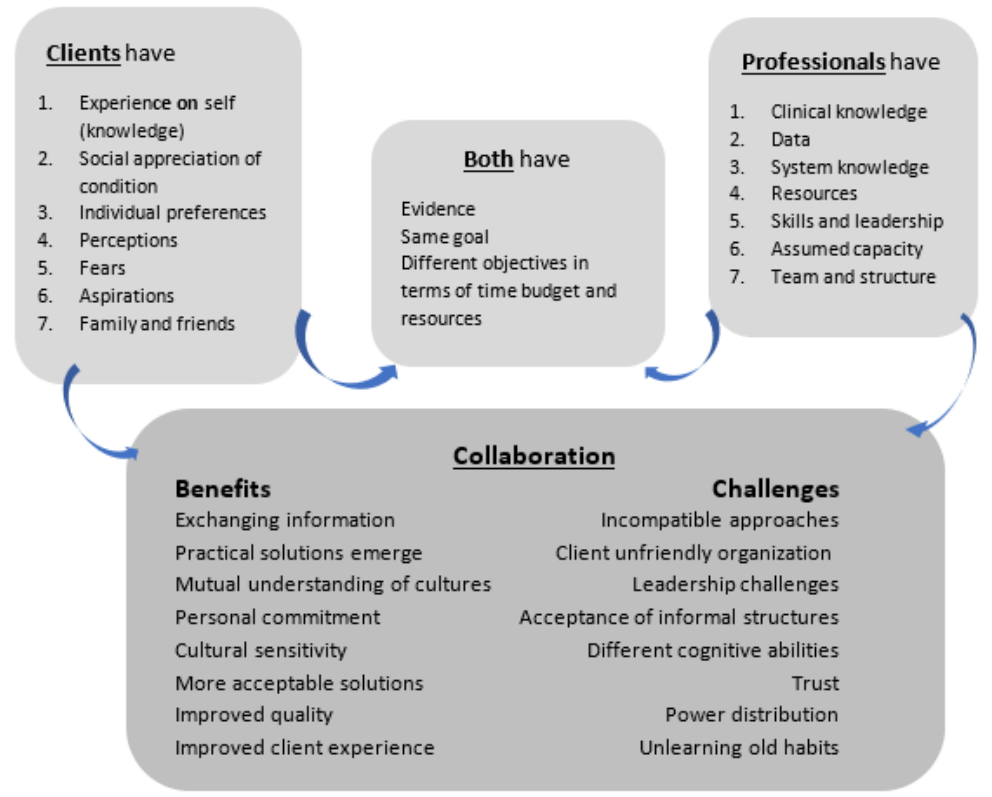

Figure 2

Bringing divergent parties to co-construct

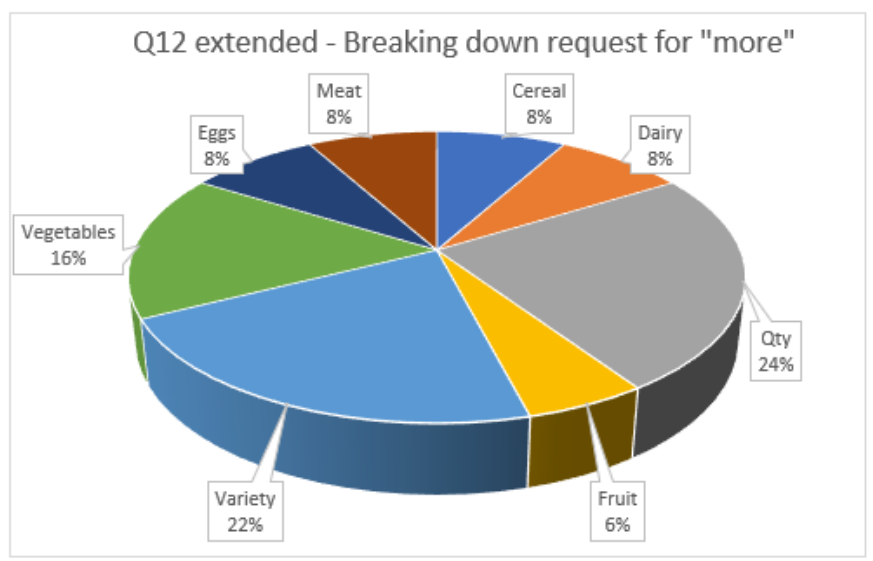

Figure 3

Additional analysis on requests for more in annual survey 